\title{
Torque Analysis of Permanent Magnet Flux Switching Machines with Rotor Step Skewing
}

\author{
Weizhong Fei ${ }^{1,2}$, Patrick Chi Kwong Luk ${ }^{1}$, Senior Member, IEEE, Jianxin Shen ${ }^{2}$, Senior Member, IEEE \\ ${ }^{1}$ School of Engineering, Cranfield University, Cranfield, Bedfordshire, MK43 0AL, U.K. \\ ${ }^{2}$ College of Electrical Engineering, Zhejiang University, Hangzhou, 310027, China
}

\begin{abstract}
This paper investigates the torque characteristics of permanent magnet flux switching (PMFS) machines with rotor step skewing. The cogging torque, torque ripple and average output torque of a PMFS machine with a common stator and different rotor pole widths and rotor pole numbers are first established using two-dimensional (2-D) finite element analysis (FEA). A cost-effective rotor step skewing technique is then proposed to reduce the cogging torque and torque ripple of the machine with two different rotors. The results have revealed that the least step number and angle for optimal torque ripple mitigation of the PMFS machine are determined by the harmonic contents of the torque pulsation and the rotor pole number. The influences of load conditions on the machine torque characteristics are carried out by varying current excitations. The corresponding three-dimensional (3-D) FEA models are constructed and experimental prototypes are built for validations.
\end{abstract}

Index Terms - Back electromotive force (EMF), cogging torque, finite element analysis (FEA), flux switching, magnetic saturation, permanent magnet, step skewing, torque ripple.

\section{INTRODUCTION}

$\mathrm{T}$ HE QUEST for high-performance electric drives, advent of cost-effective computer systems with highly sophisticated motor design software, and advances in high-strength rareearth permanent magnet (PM) materials, have all contributed in opening up new realms for novel topology developments of PM machines. One such example is found in the permanent magnet flux switching (PMFS) machine, which was first introduced in 1955 [1]. In the PMFS machine, all the excitation sources such as PMs and armature windings are disposed on the salient-pole stator. Thus, simple thermal management can be easily achieved. The passive salient-pole rotor, similar to that of the switched reluctance machine, has a simple and rugged structure [2]. Furthermore, the PMFS machine possesses some other merits such as high torque density, high efficiency and good flux-weakening capability [3]. As the interests in the machine grow, new analytical methods involving nonlinear lumped parameter magnetic circuit models are being developed to promptly and accurately evaluate the performances of PMFS machines [4]-[7]. However, finite element analysis (FEA) of electrical machine is being well developed and used [8]-[10], hence it becomes the most common method for PMFS machine design and analysis. In the last decade, PMFS machines with various configurations have been developed for applications ranging from the domestic appliances market to the aerospace industry [11]-[19]. Meanwhile, there has been a large body of work in the area of optimization of different machine parameters including rotor pole width, winding configuration, and stator and rotor pole combination, where comprehensive

Manuscript received March 02, 2012; revised April 30, 2012; accepted May 01, 2012. Date of publication $* * * * * *, 2012$; date of current version $* * * * * *$, 2012. Corresponding author: Jianxin Shen (e-mail: j_x_shen@zju.edu.cn).

Color versions of one or more of the figures in this paper are available online at http://ieeexplore.ieee.org

Digital Object Identifier inserted by IEEE comparisons are made to show their relative impacts on the electromagnetic performance of the PMFS machines [20]-[25].

Due to the high air gap flux density, together with the doubly salient structure of the PMFS machine, there will be severe magnetic saturations developed in the machine's teeth. The saturations result in parasitic torque pulsations which vary periodically with rotor position and lead to speed fluctuations, which is a major disadvantage of the PMFS machine. In general, torque ripple causes mechanical vibration and acoustic noise, and could deteriorate the machine's performance and even cause failures. The torque ripple in the PMFS machine originates from three main sources: 1) cogging torque generated by the PM field energy variations with rotor position, 2) torque produced by the interaction between the magnetic fields by winding currents and the PMs, and 3) reluctance torque produced by winding inductance alterations with rotor position. Accordingly, torque ripple minimization techniques can be divided into two different categories: control-based or design-based [26]. The former usually involves sophisticated real-time controller to precisely profile and feed the required current excitation, while the latter generally concerns design optimization of the geometric parameters of the machine. Normally, the design-based techniques are more effective yet economical than the controlbased ones, which invariably involve costly, reliable and accurate sensors. Torque ripple reduction is of particular importance in PMFS machine for high performance low-speed or high-precision position control applications. Compared with conventional PM brushless machine, there are relatively exiguous researches addressing the issues of torque ripple minimization in PMFS machines from either machine control [27] or design [28-31] perspectives. Due to the relatively simple rotor structure of the PMFS machine, optimal rotor design techniques, which are usually simple and cost effective, are much more preferable to alleviate the cogging torque and torque ripple of PMFS machine.

In this paper, the key parameters of the PMFS machine 


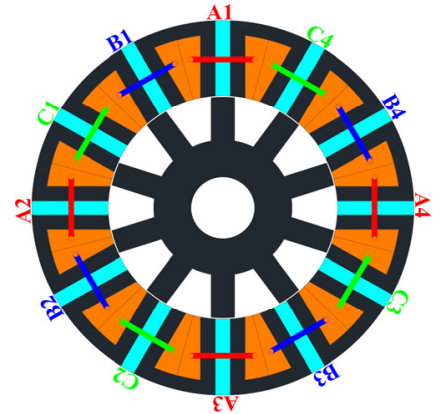

(a)

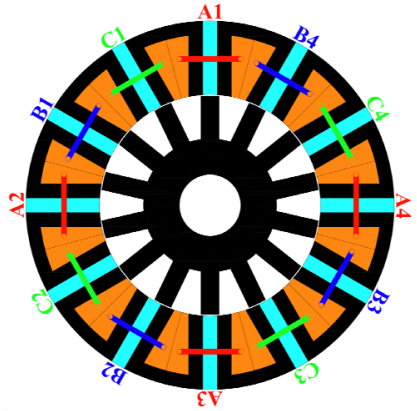

(b)
Fig. 1. Schematic of the proposed permanent magnet flux switching machines. (a) $12 / 10$ stator/rotor pole topology. (b) $12 / 14$ stator/rotor pole topology.

TABLE I

MAIN DESIGN PARAMETERS OF THE PMFS MACHINE

\begin{tabular}{cccc}
\hline \hline Symbol & Machine Parameter & Values & Unit \\
\hline$p$ & Phase number & 3 & - \\
$N_{s}$ & Stator pole number & 12 & - \\
$N_{r}$ & Rotor pole number & $10 / 14$ & - \\
$N$ & Coil turn number & 6 & - \\
PM & Magnet material & NdFeB35 & - \\
$R_{s o}$ & Stator outer radius & 46.00 & $\mathrm{~mm}$ \\
$R_{r o}$ & Rotor outer radius & 24.75 & $\mathrm{~mm}$ \\
$g$ & Air gap length & 0.50 & $\mathrm{~mm}$ \\
$h_{p m}$ & Magnet thickness & 3.24 & $\mathrm{~mm}$ \\
$h_{p r}$ & Rotor tooth height & 6.06 & $\mathrm{~mm}$ \\
$l_{a}$ & Machine stack length & 60 & $\mathrm{~mm}$ \\
$n_{r}$ & Rated rotational speed & 1000 & $\mathrm{rpm}$ \\
$T_{r a}$ & Rated output torque & $5.6 / 6.4$ & $\mathrm{~N} \cdot \mathrm{m}$ \\
$I_{r}$ & Rated phase current & $50(\mathrm{peak})$ & $\mathrm{A}$ \\
\hline \hline
\end{tabular}

under study are first introduced and modelling approaches of torque ripple are discussed. Then the effects of the rotor pole width and rotor pole number on torque characteristics such as cogging torque, torque ripple and output torque are determined using two-dimensional (2-D) FEA. The expedient rotor step skewing technique is proposed and thoroughly investigated into its effectiveness to mitigate the cogging torque and torque ripple of the PMFS machine. The influences of stator current excitation on the machine torque characteristics are also examined and presented in 2-D FEA results. Moreover, threedimensional (3-D) FEA models, which take into account the end effects of the machine as well as the axial interactions between the rotor steps, are carried out to validate the corresponding 2-D FEA results. Finally, two prototype machines with 10-pole rotors are built and experimental results are undertaken to underpin the validity of the FEA results. The results not only verify that the cogging torque and torque ripple of the PMFS machine can be effectively suppressed, but also reveal that the optimal least step number and angle are closely related to the harmonic contents of the torque pulsation and rotor pole number.

\section{PMFS MACHINE AND TORQUE RIPPLE MODELING}

The PMFS machines under study are illustrated in Fig.1. It can be found that the two machines share a common elaborate stator of twelve poles with embedded rectangular PMs and concentrated coils, with each possesses a robust and passive rotor of 10 and 14 poles respectively. The operation principle and general design guideline of such PMFS machines can be found in [2], while the detailed design and performance analysis of the proposed machine have been reported in [32]. The key design parameters of the PMFS machine, on which the torque ripple reduction and analysis in this study are based, are given in Table I.

The PMFS machines, which inherently use unique doubly salient structure, still suffer from the inevitable torque ripple. Based on the previous discussions, there are generally two types of torque ripple: the load-independent cogging torque and load-dependent torque pulsations. The cogging torque in PMFS machines, which originates from the tendency of the passive and salient rotor to align itself with minimum PM field energy by altering positions between the rotor and stator, is load-independent. The torque acting on single stator pole in the PMFS machine without stator armature excitations can be expressed as

$$
T_{c \mathrm{~s}}(\theta)=\sum_{n=1}^{\infty} T_{c n} \sin \left(n N_{r} \theta\right)
$$

where $N_{r}$ is the rotor pole number, $T_{c n}$ is the amplitude of the corresponding $n^{\text {th }}$ torque harmonics, and $\theta$ is the rotor position relative to the middle of stator pole. The resultant cogging torque of the machine can subsequently be calculated by summing $T_{c s}$ of all stator poles as

$T_{c}(\theta)=\sum_{n=1}^{\infty} \sum_{k=0}^{N_{s}-1} \cos \left(\frac{2 k n N_{r} \pi}{N_{s}}\right) T_{c n} \sin \left(n N_{r} \theta\right)$

By inspection, one finds only the terms in which $n N_{r} / N_{s}$ are integers are not equal to zero. In other words, the fundamental frequency of the cogging torque is the least common multiple of $N_{r}$ and $N_{s}, \operatorname{lcm}\left(N_{r}, N_{s}\right)$. For the sake of clarity, the loaddependent torque pulsations will be treated as a whole. Moreover, in this paper pure sinusoidal excitation current will be used in the analysis. This will then decouple any controller effects from the torque ripple. Based on space-time transformation [33], the torque acting on a single stator pole with load condition can be derived by synthesizing the loadindependent and load-dependent components as

$$
T_{s}(\theta)=T_{c s}(\theta)+\sum_{n=0}^{\infty} T_{s n}\left(I_{p}, \varphi_{p}\right) \sin \left[n N_{r} \theta+\varphi_{s n}\left(I_{p}, \varphi_{p}\right)\right]
$$

where $T_{s n}\left(I_{p}, \varphi_{p}\right)$, and $\varphi_{s n}\left(I_{p}, \varphi_{p}\right)$ are the amplitude and phase angle of the $n^{\text {th }}$ harmonic of the torque on single stator pole generated by phase current with amplitude $I_{p}$ and phase angle $\varphi_{p}$. Thus, the total torque of the machine can be synthesized as

$$
\begin{aligned}
& T(\theta)=\sum_{n=1}^{\infty} \sum_{k=0}^{N_{s}-1} \cos \left(\frac{2 k n N_{r} \pi}{N_{s}}\right) T_{c n} \sin \left(n N_{r} \theta\right) \\
& +\sum_{n=0}^{\infty} \sum_{k=0}^{N_{s}-1} \cos \left(\frac{2 k n N_{r} \pi}{N_{s}}\right) T_{s n}\left(I_{p}, \varphi_{p}\right) \sin \left[n N_{r} \theta+\varphi_{s n}\left(I_{p}, \varphi_{p}\right)\right] .
\end{aligned}
$$

It can be inspected that the fundamental period of the overall torque ripple is the same as that of the cogging torque. The 


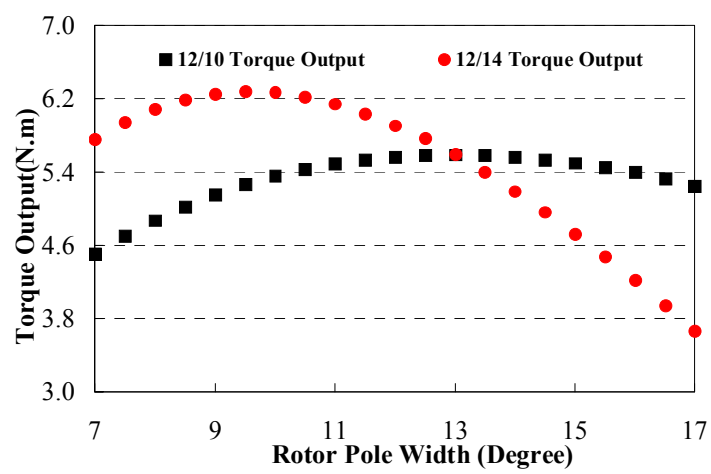

Fig. 2. The average torque outputs of the proposed machines with different rotor pole width at rated excitations.

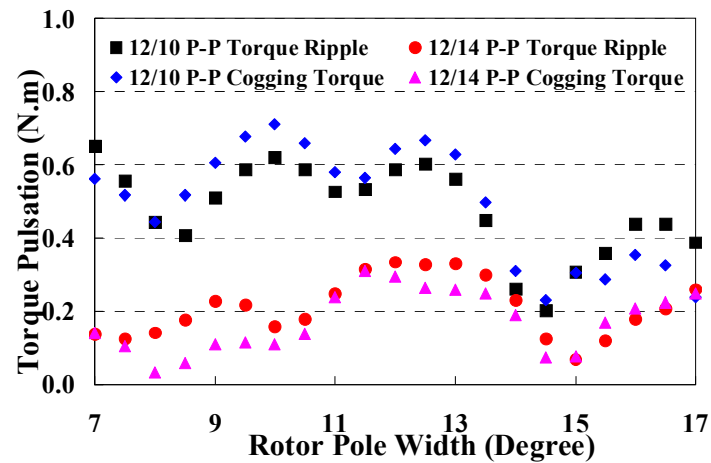

Fig. 3. The P-P cogging torque and torque ripple of the proposed machines with different rotor pole width at rated excitations.

main components of the local stator pole torque contributing to the cogging torque and torque ripple should be minimized by different rotor design techniques such as rotor pole width optimization and rotor step skewing.

\section{Rotor Pole WIDTH}

The rotor pole width greatly influences the performance of PMFS machine. The impacts of the rotor pole width on back electromotive force (EMF) in a PMFS machine with a 12/10 stator/rotor pole topology have been studied and revealed by 2-D FEA and experimental results [20]. Furthermore, the optimal values of rotor pole width for maximum torque output and minimum cogging torque and torque ripple are always attainable. However, they normally are not the same [4]. Consequently, compromise between the quantity and quality of the output torque would be inevitable during machine design stage.

The PMFS machines under study have a rather distinctive doubly salient structure. However the direct-axis and quadrature-axis reluctances of such a PMFS machine are similar in magnitude such that the exploitable reluctance torque is almost negligible [4]. Without loss of generality, the phase angle of the armature current is set to zero in order to simplify the analysis in this section. With the rated current of 50A (peak) excited in the stator phase windings, the average torque output values of the proposed two machines with different rotor pole widths are evaluated by 2-D FEA and comparisons are shown in Fig.2. It can be seen that the optimal rotor pole width for maximum torque output in the

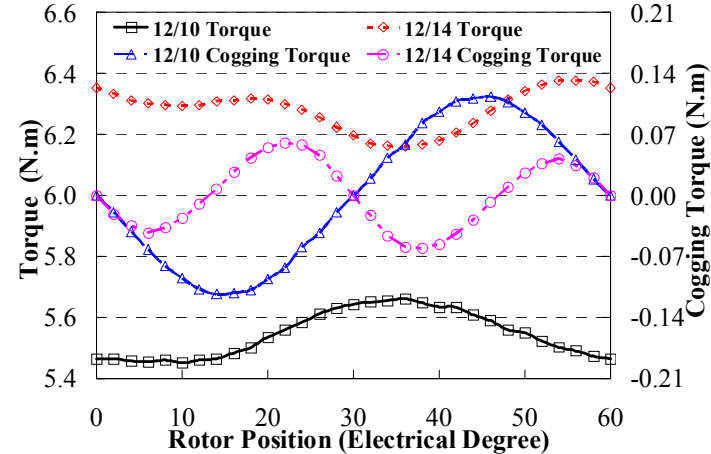

Fig. 4. The cogging torque and torque profiles of the two machines with the corresponding optimal rotor pole widths.

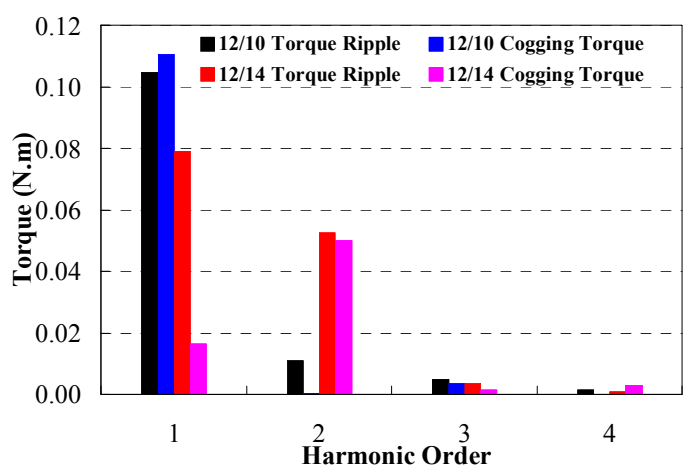

Fig. 5. The main harmonic components of the cogging torque and torque ripple of the two machines with corresponding rotor pole widths.

$12 / 10$ machine are much larger than the one in the $12 / 14$ machine. Higher torque can be generated in the $12 / 14$ machine until the rotor pole width reaches 13 degrees and the disparity is quite significant as the rotor pole width is small. However, the output torque of the $12 / 14$ machine declines steeply as the rotor pole width goes beyond 12.5 degrees, while that of the $12 / 10$ machine more or less maintains the magnitude. The range of rotor pole width for the $12 / 10$ machine to generate torque less than one percent difference from the optimal one is from 11.5 to 14.5 degrees, which is much broader than the one from 9 to 10.5 degrees for the 12/14 machine. Meanwhile, Fig. 3 sheds some light on the effects of the rotor pole width on the cogging torque and torque ripple by showing their peak-topeak (P-P) values versus the rotor pole width. It can readily be seen that the rotor pole width greatly influences the torque characteristics in both machines. The P-P cogging torque values sometimes even exceed the P-P torque ripple ones, especially for the 12/10 machine. This observation hints that the load-dependent torque pulsations might counteract with the load-independent ones [31]. By and large, the torque pulsations are much less significant in the 12/14 machine.

Based on the preceding analysis, the rotor pole widths of 14.25 and 9.25 degrees are selected for the study hereinafter by considering the overall torque output and torque ripple performance in the $12 / 10$ and $12 / 14$ machines respectively. The predicted torque profiles at rated current excitation of the two machines, together with their cogging torque waveforms are plotted in a periodic interval of 60 electrical degrees as shown in Fig.4. Furthermore, the main harmonic components 


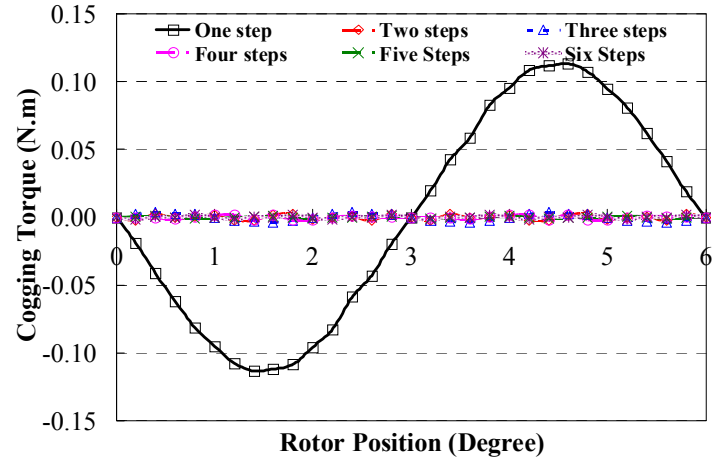

Fig. 6. The cogging torque profiles of the $12 / 10$ machine with different rotor skewing steps and corresponding skewing angles.

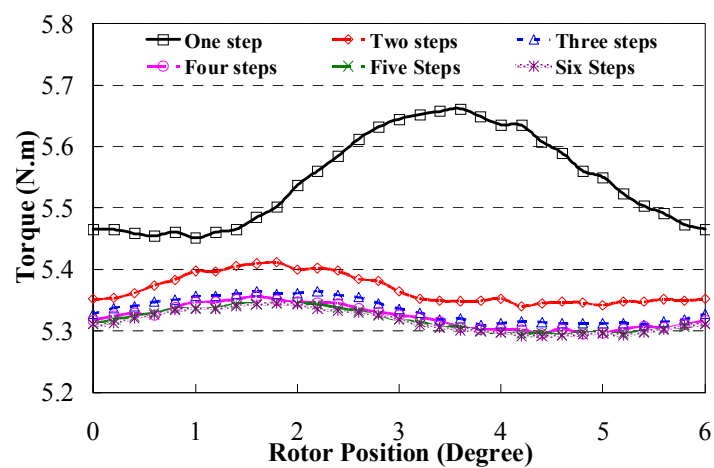

Fig. 7. The torque profiles of the $12 / 10$ machine with different rotor skewing steps and corresponding optimal skewing angles at rated excitations.

of the waveforms are computed and illustrated in Fig.5. In the $12 / 10$ machine, the fundamental component of the cogging torque is the dominant contributor for both cogging toque and torque ripple, and the load-dependent part places a very slight impact on the resultant torque ripple. In the 12/14 machine, the second harmonic instead of the fundamental one, is the prevailing component of the cogging torque. The loaddependent torque pulsations impose additional contributions to the torque ripple in terms of elevated fundamental component. The P-P torque ripple values in the two machines are nearly the same, while the cogging torque in $12 / 10$ machine is twice greater than the one in the 12/14 machine.

\section{ROTOR STEP SKEWING}

Generally, the selection of a torque ripple reduction technique should take into account the issues of complexity and hence the costs of implementation as well as the impact on machine performance such as output torque. Thus, the rotor design based techniques are more preferable as a result of the complex stator structure of the proposed PMFS machines.

\section{A. Modeling of Rotor Step Skewing}

As an alternative to the effective rotor skewing one, the rotor step skewing technique, which arranges the rotor axially in discrete steps, is employed in this paper to further reduce the torque ripple of the proposed PMFS machines. The rotor step skewing technique can be essentially treated as several identical machines with circumferentially and successively shifted rotors axially conjoined together. By neglecting the

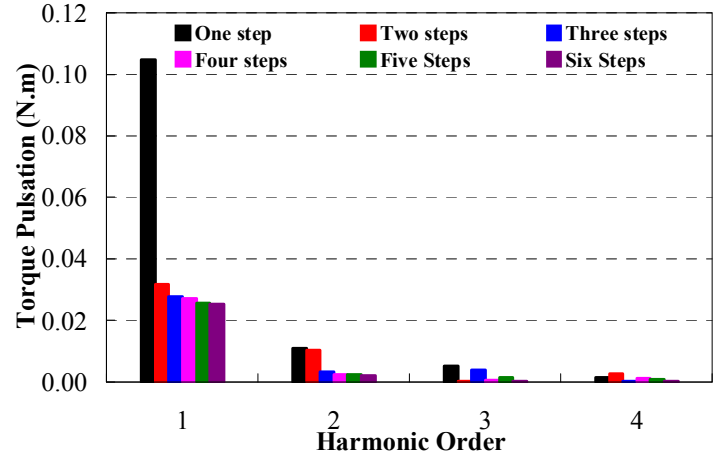

Fig. 8. The main harmonic components of the torque ripple of the $12 / 10$ machine with different rotor skewing steps.

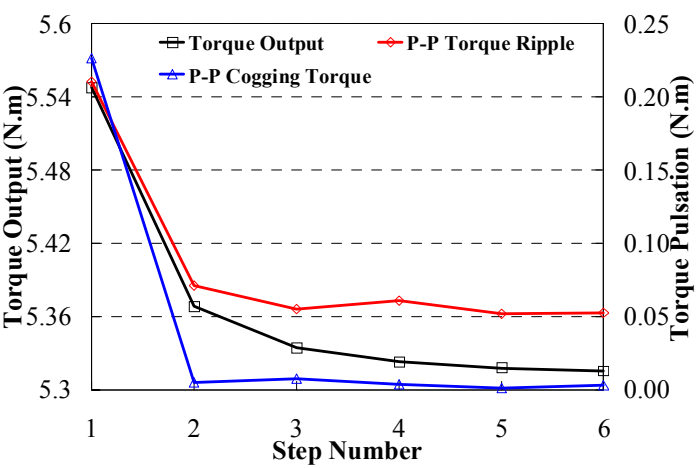

Fig. 9. The torque output, P-P cogging torque, and P-P torque ripple variations with rotor skewing step number in the $12 / 10$ machine.

axial interactions between the steps, the resultant cogging torque of the machine with rotor step skewing can be obtained by synthesizing the cogging torque produced by each step as

$T_{c}(\theta)=\sum_{n=1}^{\infty} \sum_{k=0}^{N_{s}-1} \frac{\sin \left(\frac{v}{2} n N_{r} \theta_{s}\right)}{v \sin \left(\frac{1}{2} n N_{r} \theta_{s}\right)} \cos \left(\frac{2 k n N_{r} \pi}{N_{s}}\right) T_{c n} \sin \left(n N_{r} \theta\right)$

where $v$ and $\theta_{s}$ are the skewing step numbers and mechanical skewing angle between the adjacent two modules. Besides, with the phase advancing concept [34], the overall torque of the machine can be expediently expressed as

$$
\begin{aligned}
& T(\theta)=\sum_{n=1}^{\infty} \sum_{k=0}^{N_{s}-1} \frac{\sin \left(\frac{v}{2} n N_{r} \theta_{s}\right)}{v \sin \left(\frac{1}{2} n N_{r} \theta_{s}\right)} \cos \left(\frac{2 k n N_{r} \pi}{N_{s}}\right) T_{c n} \sin \left(n N_{r} \theta\right) \\
&+\sum_{n=0}^{\infty} \sum_{k=0}^{N_{s}-1} \sum_{j=0}^{v-1} \frac{1}{v} \cos \left(\frac{2 k n N_{r} \pi}{N_{s}}\right) T_{s n}\left(I_{p}, \varphi_{p}-\frac{v-2 j-1}{2} \theta_{s}\right) \\
& \quad \times \sin \left[n N_{r} \theta+\varphi_{s n}\left(I_{p}, \varphi_{p}-\frac{v-2 j-1}{2} \theta_{s}\right)\right] .
\end{aligned}
$$

By inspection, all the cogging torque harmonics can actually be eliminated except those which are multiples of $v$ with the skewing angle as 


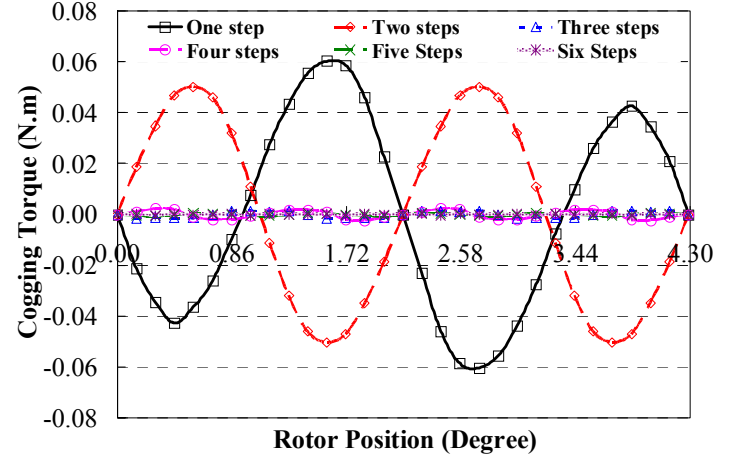

Fig. 10. The cogging torque profiles of the $12 / 14$ machine with different rotor skewing steps and corresponding skewing angles.

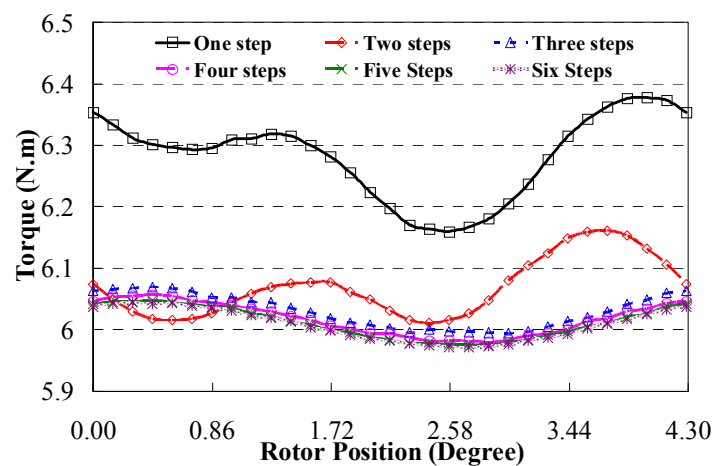

Fig. 11. The torque profiles of the $12 / 14$ machine with different rotor skewing steps and corresponding optimal skewing angles at rated excitations.

$\theta_{s}=\frac{2 k \pi}{v \operatorname{lcm}\left(N_{r}, N_{s}\right)}, \quad k=1,2,3 \ldots$

where $k$ normally should be kept as small as unity in order to prevent the machine performance from deteriorating beyond an optimal limit. However, the effect of the rotor step skewing on load-dependent torque pulsations is not readily apparent from equation (6). It could also be found from the aforesaid section that the contributions of the cogging torque to the overall torque ripple of the proposed PMFS machines are of great significance. Therefore, the skewing angle from equation (7) could be employed to effectively alleviate the torque ripple as well.

\section{B. Influence of Rotor Skewing Step Numbers}

With the corresponding step skewing angles derived from equation (7), the machines with up to six rotor skewing steps are comprehensively investigated by the synthesized 2-D FEA method [31]. The results have showed that the least skewing step numbers for the optimal torque ripple mitigation in the proposed PMFS machines are generally determined by the harmonic contents of the corresponding torque ripple.

1) The 12/10 PMFS Machine

The cogging torque and torque profiles of the 12/10 PMFS machine with rotor skewing steps ranged from one to six are estimated and compared in Fig.6 and Fig.7 respectively. Fig.6 shows that the cogging torque can be practically eliminated in the machines with more than one skewing step, which comports with the results in Fig.5 that the fundamental

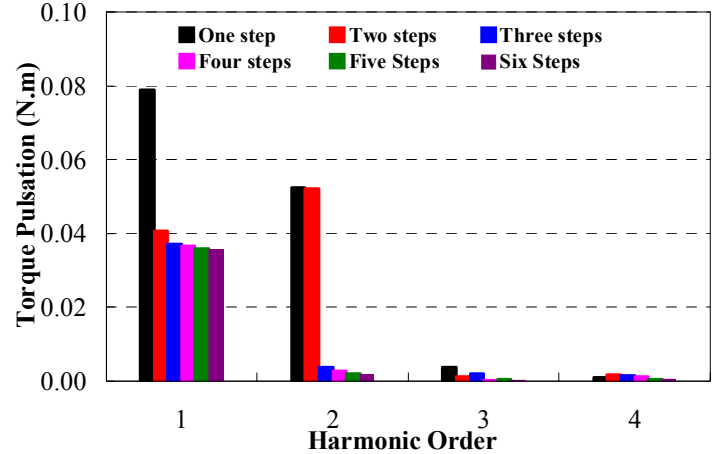

Fig. 12. The main harmonic components of the torque ripple of the $12 / 14$ machine with different rotor skewing steps.

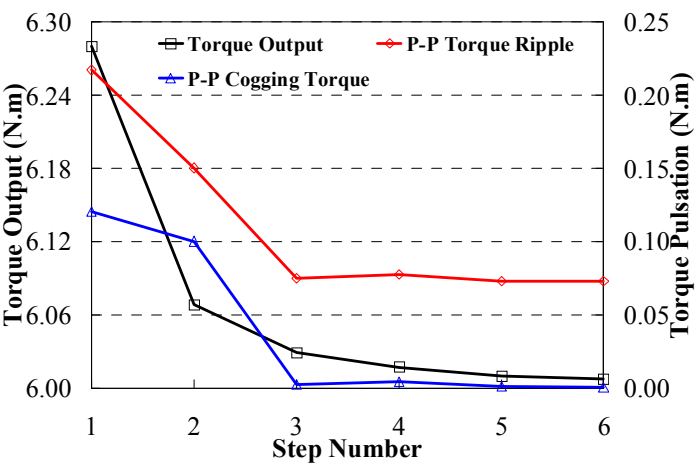

Fig. 13. The torque output, P-P cogging torque, and P-P torque ripple variations with rotor skewing step number in the $12 / 14$ machine.

harmonic is the only dominant part of the cogging torque in the 12/10 machine. It is observed from Fig. 7 that the torque ripple can be substantially suppressed as the rotor skewing step is more than one. Moreover, the main harmonic components of the torque profiles in Fig.7 are plotted in Fig.8, which validates that the harmonics of the torque ripple could be significantly reduced except the multiples of the skewing step number. The torque output, P-P cogging torque and P-P torque ripple values versus rotor skewing step number of the 12/10 machine are collectively plotted in Fig.9. It can be perceived that the average torque output would experience a considerable drop from one to two skewing steps and gradually decline as the rotor skewing step number further increases. Meanwhile, both the cogging torque and torque ripple of the machines with two to six rotor skewing steps could be effectively reduced to same extent. In addition, the rotor skewing step number should be as small as possible in order to simplify the implementation. Therefore, at least two discrete rotor steps shifted by 3 degrees are deemed adequate and optimal to curtail the cogging torque and torque ripple in the proposed 12/10 PMFS machine.

\section{2) The 12/14 PMFS Machine}

Fig.10 and Fig.11 show the predicted cogging torque and output torque profiles of the 12/14 PMFS machines with up to six skewing steps respectively. Both the cogging torque and torque ripple in the 12/14 PMFS machine would still maintain a thriving magnitude with two rotor skewing steps. As the skewing step number exceeds two, the cogging torque would be virtually eliminated and the torque ripple can be effectively 


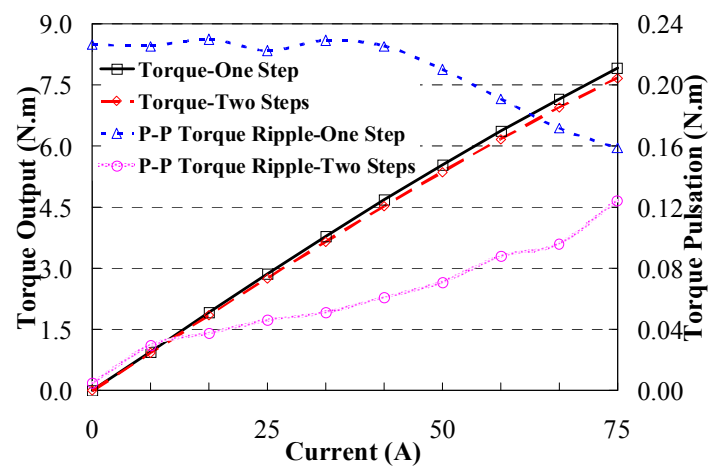

Fig. 14. The torque output, P-P cogging torque, and P-P torque ripple variations with current excitations in the $12 / 10$ machines.

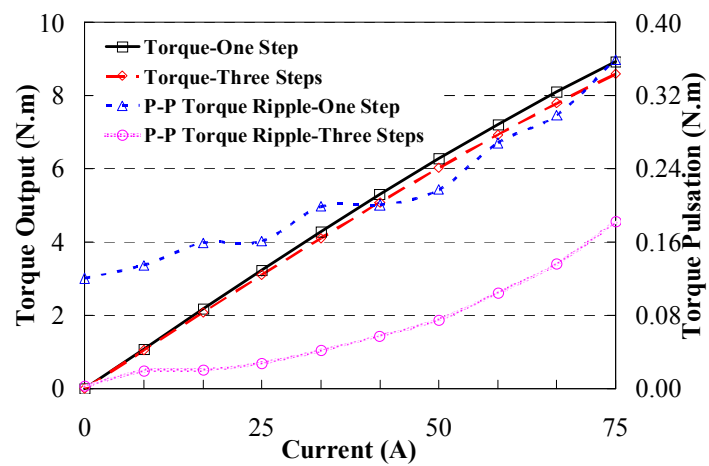

Fig. 15. The torque output, P-P cogging torque, and P-P torque ripple variations with current excitations in the $12 / 14$ machines.

alleviated. The results are in well response to the appreciable second harmonics of the torque ripple in the 12/14 PMFS machine in Fig.5. The major harmonic components of the torque ripple in the $12 / 14$ machines with different skewing step numbers are shown in Fig.12, which highlights the influence of rotor skewing step number on each harmonic component. The fundamental harmonic of the torque ripple could be merely reduced to about half, while the higher harmonic components especially the second one could be drastically curtailed with appropriate rotor skewing step numbers. The output torque, P-P cogging torque and torque ripple versus the rotor skewing step number of the 12/14 machine are collectively plotted and summarized in Fig.13. It is apparent that the shape of the average output torque variation profile in the $12 / 14$ machine is almost the same as its counterpart in the $12 / 10$ machine but the cogging torque and torque ripple would not be substantially suppressed until the rotor skewing step number reaches three. With invariable performance tradeoffs, it is unequivocal that the least rotor skewing step number and angle for optimal torque ripple reduction of the 12/14 machine are three and 1.42 degrees respectively.

\section{Influence of Current Excitations}

Severe magnetic saturation, an inherent feature of the unique PMFS machine structure, can adversely affect the torque output and induce additional torque pulsations. The situation would deteriorate even further as the stator armature current increases. The torque characteristics of the machines

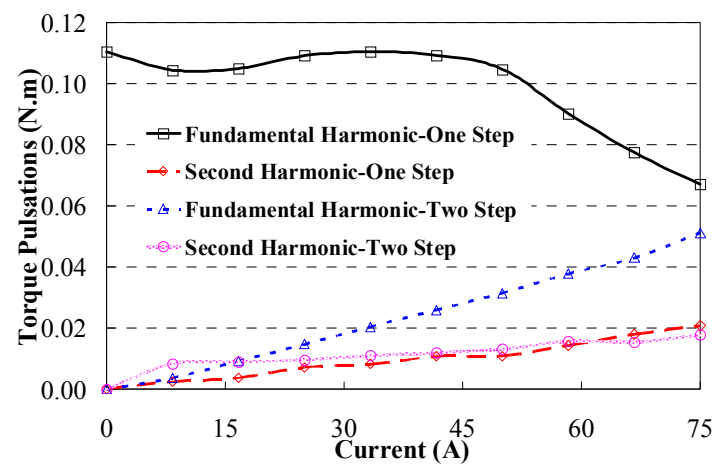

Fig. 16. Fundamental and second torque ripple harmonic variations with current excitations in the $12 / 10$ machines.

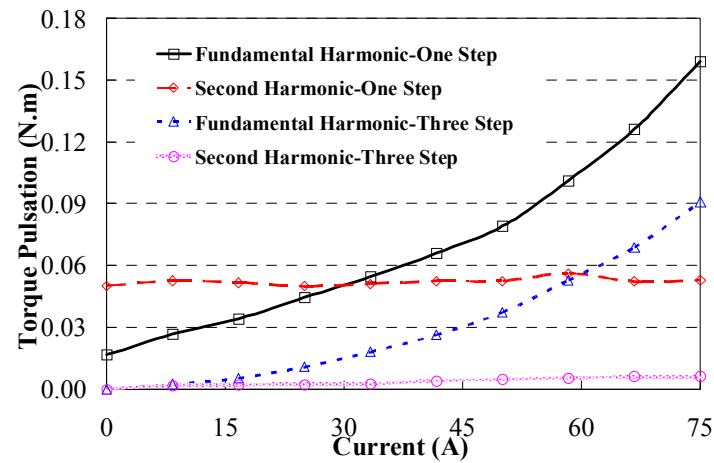

Fig. 17. Fundamental and second torque ripple harmonic variations with current excitations in the $12 / 14$ machines.

excited with various current amplitudes are analyzed in detail by synthesized 2-D FEA. Without loss of generality, only the machines with uniform and optimally step skewed rotors are investigated. The torque characteristics, such as the average output torque, P-P cogging torque and torque ripple values, in the $12 / 10$ and 12/14 machines are evaluated with different armature current excitations and are shown in Fig.14 and Fig. 15 respectively. It could be inspected from both the figures that the average torque outputs of the rotor step skewing machines are somewhat depreciated while the corresponding $\mathrm{P}-\mathrm{P}$ torque ripple values are evidently attenuated. The P-P values of the torque ripple in the unskewed 12/10 machine almost remain constant and then start to decline gradually after the current reaches $40 \mathrm{~A}$. It can be inferred that the cogging torque could be offset by the countervailing factor of loaddependent torque pulsations at high current excitations in this machine. Contrarily, the load-dependent torque pulsations in the other three machines turn into the availing contributors of torque ripple so that the P-P values of torque ripple increase with the ascending current. With an aim of gaining further insight, the impacts of the stator armature current excitation on the fundamental and second harmonic components (major ones) of the torque ripple in the machines are further investigated and the results are unveiled in Fig.16 and Fig.17 respectively. Since it has ascendancy over the other harmonics, the fundamental torque ripple harmonic variation in the unskewed 12/10 PMFS machine still follows nearly the same profile as the P-P torque ripple value one in Fig. 14 despite the fact that the second harmonic component rises steadily with 


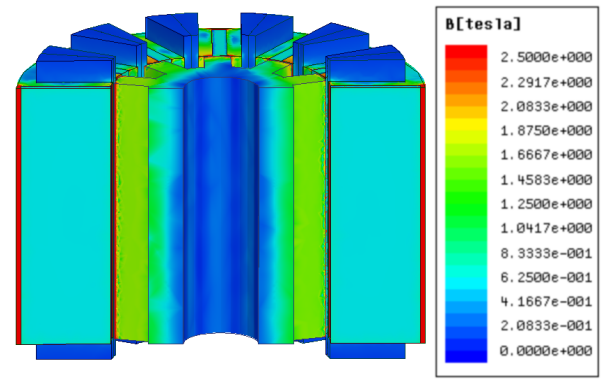

(a)

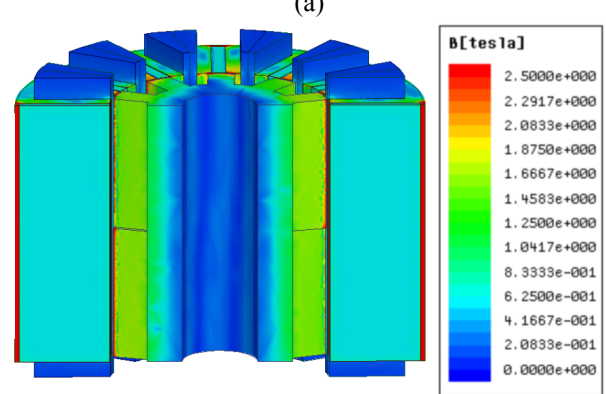

(b)

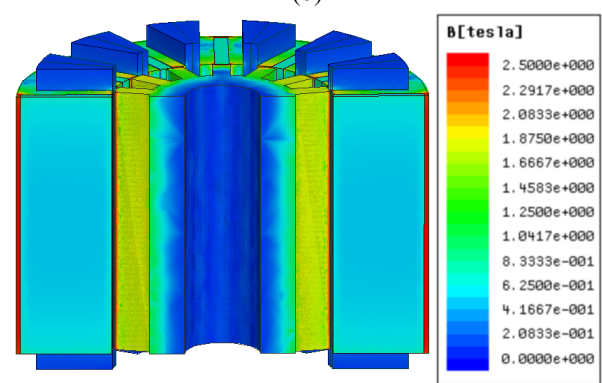

(c)

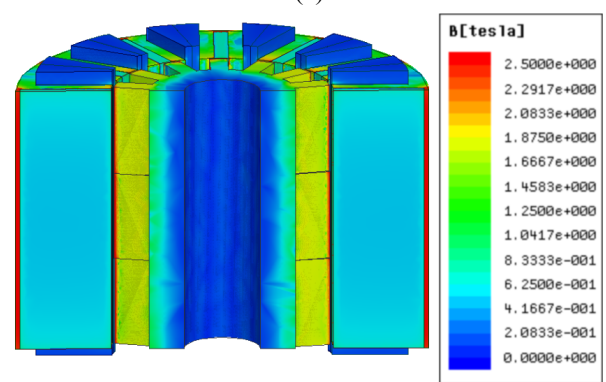

(d)

Fig. 18. The flux density distributions of the machines at no load condition from 3-D FEA results, (a) 12/10 machine with uniform rotor, (b) $12 / 10$ machine with two skewing step rotor, (c) 12/14 machine with uniform rotor, (d) $12 / 14$ machine with three skewing step rotor.

the current. However, the stator armature current would enhance both the fundamental and second torque ripple harmonics in the step skewed 12/10 machine. In the meantime, the second harmonic components of the torque ripple in both the 12/14 PMFS machines almost remain unchanged while the fundamental ones are quickly boosted as the current excitation mounts up.

\section{3-D FEA Validation}

The comprehensive 3-D FEA models, which account for the end effects of the PMFS machine and the axial interactions between the rotor steps, are crucial for more accurate cogging torque and torque ripple predictions. By exploiting the

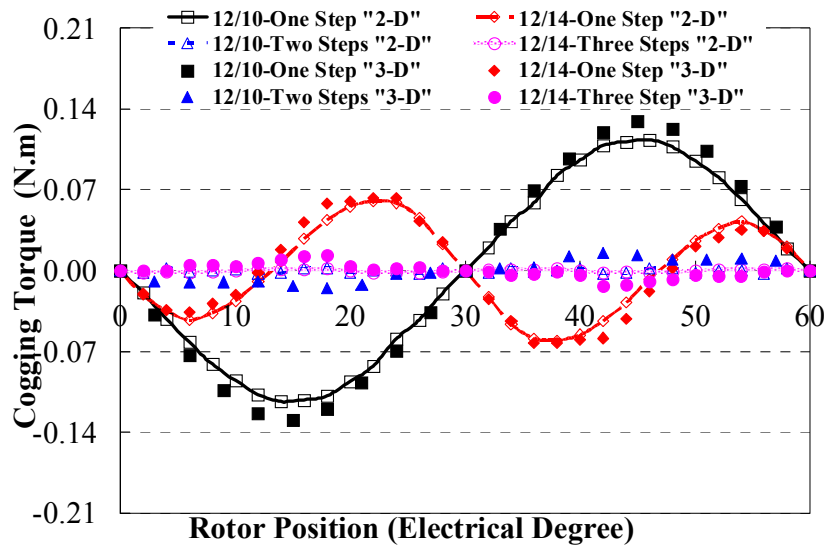

Fig. 19. The cogging torque waveforms of the 12/10 and 12/14 PMFS machines from 2-D and 3-D FEAs.

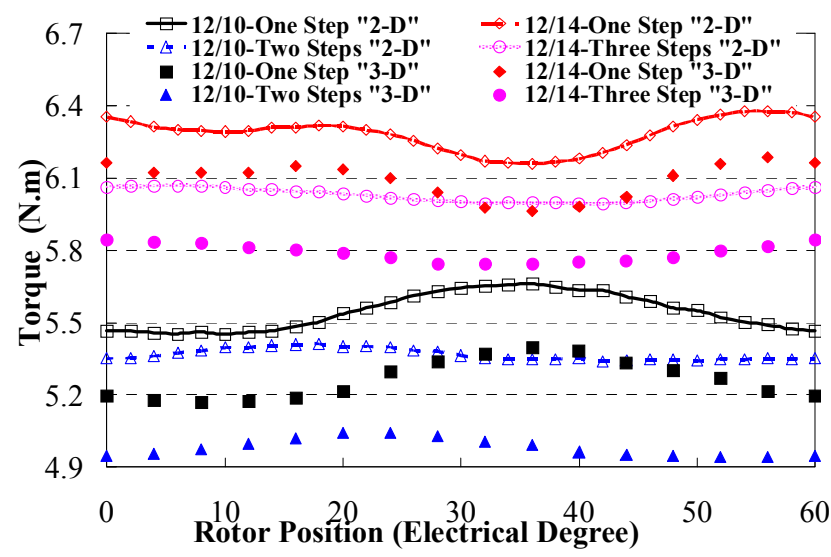

Fig. 20. The torque waveforms of the $12 / 10$ and 12/14 PMFS machines from 2-D and 3-D FEAs.

TABLE II

TORQUE CHARACTERISTICS OF THE MACHINES FROM 2-D AND 3-D FEA

\begin{tabular}{cccc}
\hline \hline Machine & Parameters & 2-D FEA & 3-D FEA \\
\hline \multirow{2}{*}{$12 / 10$} & P-P Cogging Torque & $0.227 \mathrm{~N} \cdot \mathrm{m}$ & $0.258 \mathrm{~N} \cdot \mathrm{m}$ \\
One-Step & P-P Torque Ripple & $0.210 \mathrm{~N} \cdot \mathrm{m}$ & $0.226 \mathrm{~N} \cdot \mathrm{m}$ \\
& Average Torque & $5.545 \mathrm{~N} \cdot \mathrm{m}$ & $5.265 \mathrm{~N} \cdot \mathrm{m}$ \\
\hline \multirow{2}{*}{$12 / 10$} & P-P Cogging Torque & $0.005 \mathrm{~N} \cdot \mathrm{m}$ & $0.030 \mathrm{~N} \cdot \mathrm{m}$ \\
Two-Steps & P-P Torque Ripple & $0.071 \mathrm{~N} \cdot \mathrm{m}$ & $0.100 \mathrm{~N} \cdot \mathrm{m}$ \\
& Average Torque & $5.368 \mathrm{~N} \cdot \mathrm{m}$ & $4.982 \mathrm{~N} \cdot \mathrm{m}$ \\
\hline \multirow{2}{*}{$12 / 14$} & P-P Cogging Torque & $0.121 \mathrm{~N} \cdot \mathrm{m}$ & $0.126 \mathrm{~N} \cdot \mathrm{m}$ \\
One-Step & P-P Torque Ripple & $0.217 \mathrm{~N} \cdot \mathrm{m}$ & $0.225 \mathrm{~N} \cdot \mathrm{m}$ \\
& Average Torque & $6.282 \mathrm{~N} \cdot \mathrm{m}$ & $6.095 \mathrm{~N} \cdot \mathrm{m}$ \\
\hline \multirow{2}{*}{$12 / 14$} & P-P Cogging Torque & $0.003 \mathrm{~N} \cdot \mathrm{m}$ & $0.026 \mathrm{~N} \cdot \mathrm{m}$ \\
Three-Steps & P-P Torque Ripple & $0.075 \mathrm{~N} \cdot \mathrm{m}$ & $0.101 \mathrm{~N} \cdot \mathrm{m}$ \\
& Average Torque & $6.031 \mathrm{~N} \cdot \mathrm{m}$ & $5.791 \mathrm{~N} \cdot \mathrm{m}$ \\
\hline \hline
\end{tabular}

periodic boundary conditions, only halves of the proposed machines are modelled for computational efficiency. The flux density distributions of the machines under no-load condition evaluated by the 3-D FEA models are illustrated in Fig.18, which show that severe magnetic saturations occur especially in the parts adjacent to the air gap and the stator rim. The estimated cogging torque profiles of the machines from 2-D and 3-D FEA models and the corresponding P-P values are compared in Fig. 19 and Table II respectively, which show the results are in good agreements and the 3-D FEA results are generally higher than the 2-D FEA ones. The fundamental harmonic components of the cogging torque are not practically eliminated in the step skewed machines due to the end effects 


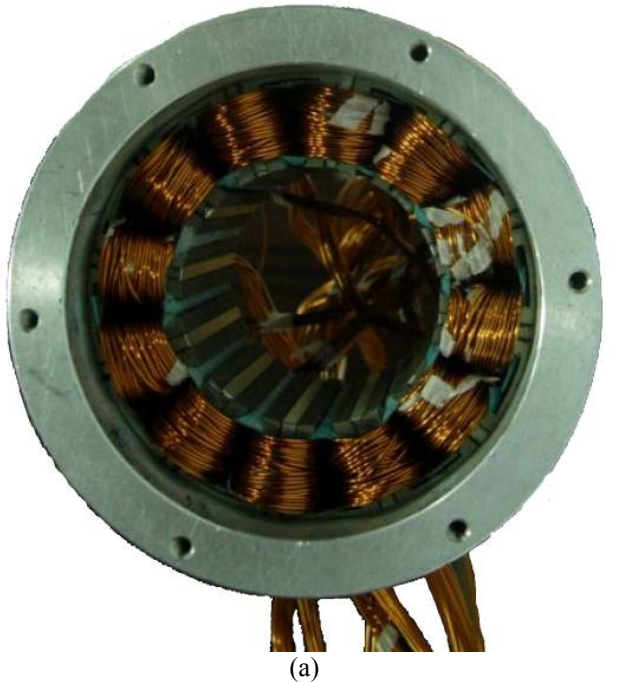

(a)

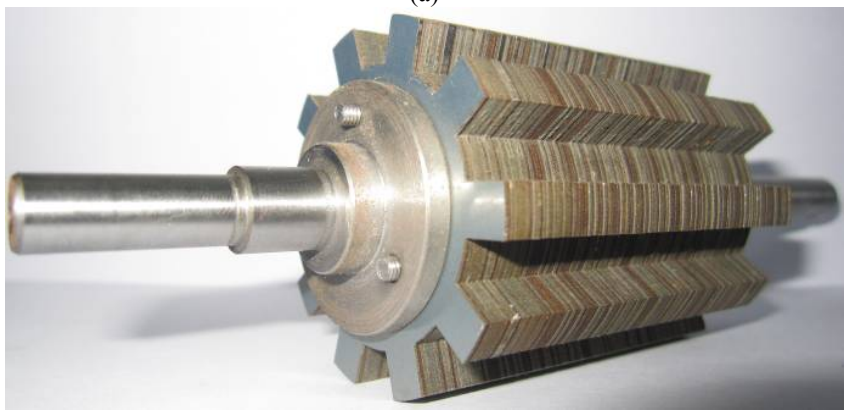

(b)

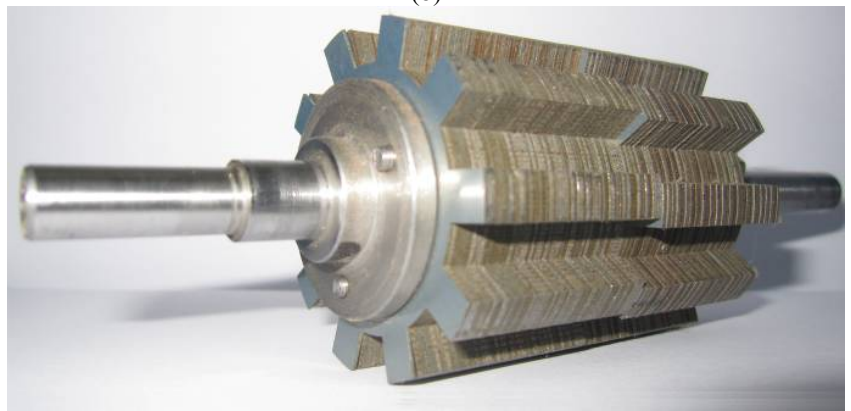

(c)

Fig. 21. The prototypes of the 12/10 PMFS machines, (a) common stator, (b) the uniform rotor with 14.25 degrees rotor pole width, (c) the rotor with twostepped skewing shifted by 3 degrees.

and axial interactions. It is underpinned by 3 -D FEA results in Fig. 19 which manifest noticeable fundamental harmonic in the corresponding cogging torque profiles. However, the 3-D FEA results confirm that the cogging torque of the PMFS machines can be drastically mitigated by rotor step skewing technique. On the other hand, the torque waveforms of the machines with rated current excitations from 2-D and 3-D FEAs are depicted in Fig.20, while the corresponding values of P-P torque ripple and average torque are given in Table II. It can be observed that reasonable agreements have been achieved and the 3-D FEA results are conceivably lower than the 2-D FEA ones due to consideration of the end effects and axial interactions. Nevertheless, the 3-D FEA results further validate that the torque ripple of the proposed PMFS machines can be reduced effectively with a trade-off of average output torque by the rotor step skewing technique. On the whole, the validity of the

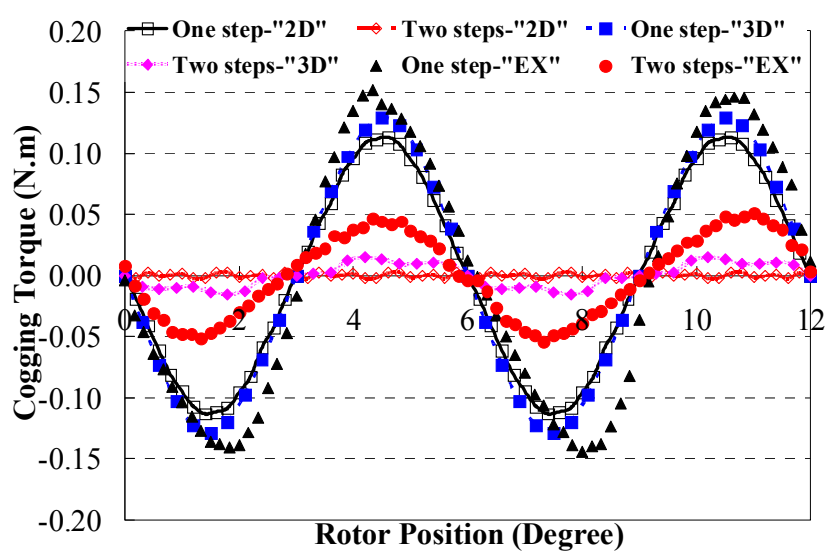

Fig. 22. The cogging torque waveforms of the 12/10 PMFS machines from 2-D, 3-D FEAs and experiment.

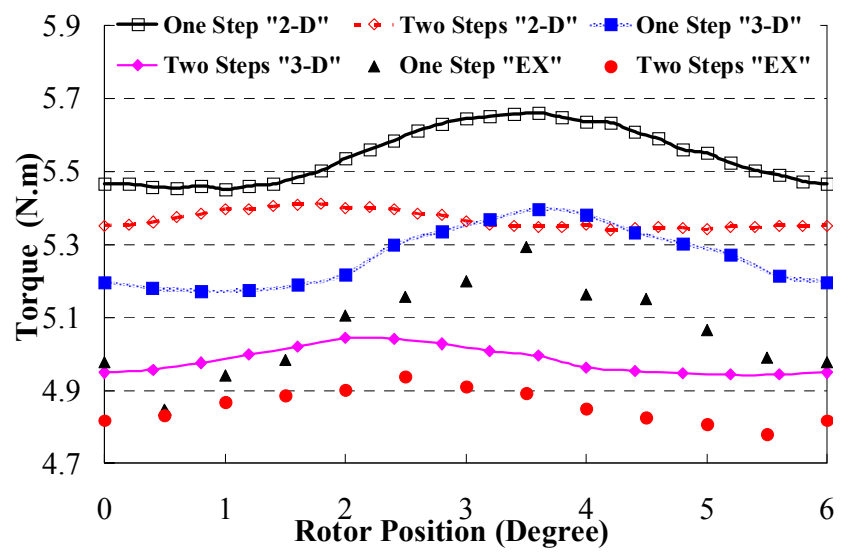

Fig. 23. The torque waveforms of the $12 / 10$ PMFS machines from 2-D, 3-D FEAs and experiment.

synthesized 2-D FEA models has been verified by the 3-D FEA ones.

\section{EXPERIMENTAL VALIDATION AND DISCUSSIONS}

The 12/10 machines with 14.25-degree rotor poles, one with the uniform rotor and one incorporating the rotor step skewing technique, have been prototyped for the validations of the FEA models, and for the verification of the rotor step skewing method for torque ripple suppression. Fig. 21 shows the photos of the common stator and the two different rotors. In Fig.21, the cogging torque profiles of the prototype machines evaluated from the FEA models are compared with the experimental results. There are glaring discrepancies between the predicted and measured results, particularly for the step skewed machine. The FEA models are hypothetically developed on the basis of perfect machines without any mechanical tolerances and assembly deficiencies. But in reality, it will be impractical to fabricate an ideal machine and the cogging torque is generally sensitive to those imperfect factors. Also accounting for errors from experiments and software, the agreements between the FEA and measured results are considered satisfactory. Moreover, the experimental results confirm that the cogging torque could be significantly reduced by the rotor step skewing technique, P-P value from $0.296 \mathrm{~N} \cdot \mathrm{m}$ to $0.105 \mathrm{~N} \cdot \mathrm{m}$, or a nearly $64.5 \%$ reduction. The 


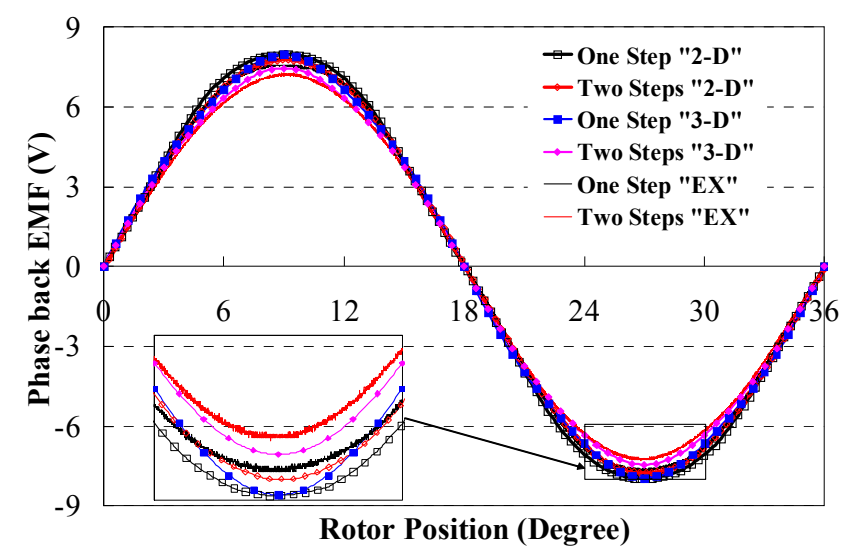

Fig. 24. The phase back EMF waveforms of the 12/10 PMFS machine from 2-D, 3-D FEAs and experiment.

TABLE III

PHASE BACK EMF HARMONIC COMPARISONS OF THE PROTOTYPES

\begin{tabular}{ccccc}
\hline \hline Prototype & Harmonic & 2-D FEA & 3-D FEA & Experiment \\
\hline \multirow{2}{*}{$12 / 10$} & Fundamental & $8.03 \mathrm{~V}$ & $7.82 \mathrm{~V}$ & $7.72 \mathrm{~V}$ \\
One-Step & Fifth & $0.151 \mathrm{~V}$ & $0.138 \mathrm{~V}$ & $0.146 \mathrm{~V}$ \\
& Seventh & $0.0290 \mathrm{~V}$ & $0.0110 \mathrm{~V}$ & $0.00440 \mathrm{~V}$ \\
\hline \multirow{2}{*}{$12 / 10$} & Fundamental & $7.75 \mathrm{~V}$ & $7.39 \mathrm{~V}$ & $7.20 \mathrm{~V}$ \\
Two-Steps & Fifth & $0.0564 \mathrm{~V}$ & $0.0697 \mathrm{~V}$ & $0.0120 \mathrm{~V}$ \\
& Seventh & $0.0135 \mathrm{~V}$ & $0.0150 \mathrm{~V}$ & $0.0224 \mathrm{~V}$ \\
\hline \hline
\end{tabular}

experimental torque waveforms of the machines under rated load condition are composed of 12 static torque measurements over a torque pulsation period of 6 degrees by exciting the 3phase winding with de current according to the rotor positions. The measured torque profiles of the prototypes at rated current of 50A (peak) are shown in Fig.23, in which the 2-D and 3-D FEA results are also included for comparisons. It can be seen that the experimental results deviate considerably from the FEA ones. During the experiments, any rotor position errors would have been amplified by ten times as the prototypes have ten rotor poles and measurement errors in the winding currents do exist. These factors, together with the ones aforementioned for cogging torque, potentially lead to more substantial experimental errors. More importantly, the experimental average torque values of the prototypes are $5.066 \mathrm{~N} \cdot \mathrm{m}$ and $4.856 \mathrm{~N} \cdot \mathrm{m}$ respectively, which are rather smaller than the estimated ones due to the lamination stack factor and friction effects. Furthermore, the measured P-P values of the prototypes are $0.447 \mathrm{~N} \cdot \mathrm{m}$ and $0.159 \mathrm{~N} \cdot \mathrm{m}$ respectively. Thus, the overall torque ripple could be effectively attenuated by $64.4 \%$ by rotor step skewing, but with the compromise of a reduction of $4.2 \%$ of the average torque output. Additionally, the phase back EMF waveforms of the prototypes from FEA results and experimental tests at the rated speed of 1000rpm are plotted and compared in Fig.24, which reveals that the measured ones are rather smaller than the predicted ones as expected and the profiles are essentially sinusoidal. The corresponding crucial harmonics (fundamental, fifth, and seventh) of the phase back EMF are derived and given in Table III for further comparison. The deviations among the fundamental harmonic values from the 2-D, 3-D FEA, and measured results comport well with the corresponding ones of average output torque. It can be noticed that the harmful fifth harmonic is significantly reduced at the expenses of slightly increased seventh one and depreciated fundamental one by rotor step skewing.

From the previous comprehensive analysis and comparisons, the optimal step number and angle are highly dependent on the rotor pole numbers and especially the harmonic contents of the torque ripple. The cost-effective rotor step skewing technique not only could drastically alleviate the cogging torque but also effectively suppress the general torque ripple. However, it should be noted that the rotor step skewing technique would inevitably compromise the torque output of the machine. Thus, it is important to undertake suitable appraisal on the pros and cons of the technique to be implemented in order to meet the specific requirements of the application.

\section{CONCLUSION}

The torque analysis on the 12/10 and 12/14 PMFS machines with different configurations has been carried out. The rotor pole width and stator/rotor pole combination of the proposed PMFS machine have significant impacts on both the harmonic contents and corresponding amplitudes of the cogging torque and torque ripple, as well as the average output torque. As a result, the optimal values of rotor pole width are determined by considering the output torque and torque ripple performance in the $12 / 10$ and $12 / 14$ machines respectively.

The rotor step skewing technique deteriorates average output torque compared with the machine with the uniform rotor. Further torque ripple reduction in the PMFS machines with step skewed rotor is an effective design measure, but requires careful selection of the step number and angle. With the corresponding optimum skewing angle, the minimum steps number to get an effective torque ripple reduction is found to be the same as the dominant torque ripple harmonic number plus one. Consequently, comprehensive torque analysis is of particular importance before the implementation of rotor step skewing technique. Finally, the experimental results obtained from the prototypes shows satisfactory agreements with the estimated results by 2-D and 3-D FEA approaches, and underpin the findings of the study.

\section{ACKNOWLEDGMENT}

This work was supported by Qiangjiang Professionals Program of Zhejiang Province (2006R10014), Natural Science Foundation of China (51077116, 50677061), and China 973 Program (2011CB707204). The project was carried out under the collaborative Memorandum of Understanding between Zhejiang University and Cranfield University.

\section{REFERENCES}

[1] S. E. Rauch, and L. J. Johnson, "Design principles of flux-switching alternators," AIEE Trans., Power Apparatus Syst. Part III, vol. 74, no. 3, pp. 1261-1268, Jan. 1955.

[2] E. Hoang, A. H. Ben-Ahmed, and J. Lucidarme, "Switching flux PM polyphased synchronous machines," in Proc. $7^{\text {th }}$ Eur. Conf. Power Electron. Appl., Sep. 1997, vol. 3, pp. 903-908.

[3] W. Hua, M. Cheng, Z. Q. Zhu, and D. Howe, "Design of flux-switching permanent magnet machine considering the limitation of inverter and flux-weakening capability," in Proc. IEEE Ind. Appl. Soc. $41^{\text {st }}$ Annu. Meet., Oct. 2006, vol. 5, pp. 2403-2410. 
[4] Z. Q. Zhu, Y. Pang, D. Howe, S. Iwasaki, R. P. Deodhar, and A. Pride, "Analysis of electromagnetic performance of flux-switching PM machines by non-linear adaptive lumped parameter magnetic circuit model," IEEE Trans. Magn., vol. 41, no. 11, pp. 4277-4287, Nov. 2005.

[5] Y. Chen, Z. Q. Zhu, and D. Howe, "Three-dimensional lumped parameter magnetic circuit model for analyzing single-phase fluxswitching PM motor," IEEE Trans. Ind. Appl., vol. 44, no. 6, pp. 17011710, Nov./Dec. 2008

[6] E. Ilhan, B. L. J. Gysen, J. J. H. Paulides, and E. A. Lomonova, "Analytical hybrid model for flux switching permanent magnet machines," IEEE Trans. Magn., vol. 46, no. 6, pp. 1762-1765, Jun. 2010

[7] J. T. Chen, and Z. Q. Zhu, "Influence of the rotor pole number on optimal parameters in flux-switching PM brushless AC machines by the lumped-parameter magnetic circuit model," IEEE Trans. Ind. Appl., vol. 46, no. 4, pp. 1381-1388, Jul./Aug. 2010.

[8] S. J. Salon, Finite Element Analysis of Electrical Machines. Kluwer Academic Publishers, 1995

[9] A. B. J. Reece, T. W. Preston, Finite Element Methods in Electrical Power Engineering. Oxford University Press, 2000

10] N. Bianchi, and L. Alberti, "MMF harmonics effect on the embedded FE analytical computation of PM motors," IEEE Trans. Ind. Appl., vol. 46 no. 2, pp. 812-820, Mar./Apr. 2010.

[11] Y. Amara, E. Hoang, M. Gabsi, M. Lecrivain, and S. Allano, "Design and comparison of different flux-switching synchronous machines for an aircraft oil breather application," Eur. Trans. Elect. Power, vol. 15, no. 6 pp. 497-511, 2005.

[12] Y. Cheng, C. Pollock, and H. Pollock, "A permanent magnet flux switching motor for low energy axial fans," in Proc. IEEE Ind. Appl. Soc. $40^{\text {th }}$ Annu. Meet., Oct. 2005, vol. 3, pp. 2168-2175.

[13] W. Fei, and J. X. Shen, "Novel permanent magnet switching flux motors," in Proc. $41^{\text {st }}$ Int. Universities Power Eng. Conf., Sep. 2006, vol. 2, pp. 729-733.

[14] Z. Q. Zhu, J. T. Chen, and D. Howe, "Analysis of a novel multi-tooth flux-switching PM brushless ac machine for high torque direct-drive applications," IEEE Trans. Magn., vol. 44, no. 11, pp. 4313-4316, Nov. 2008.

[15] A. S. Thomas, Z. Q. Zhu, R. L. Owen, G. W. Jewell, and David Howe, "Multiphase flux-switching permanent-magnet brushless machine for aerospace application," IEEE Trans. Ind. Appl.., vol. 45, no. 6, pp. 1071 1981, Nov./Dec. 2009

[16] R. L. Owen, Z. Q. Zhu, A. S. Thomas, G. W. Jewell, and D. Howe, "Alternate poles wound flux-switching permanent-magnet brushless AC machines," IEEE Trans. Ind. Appl.., vol. 46, no. 2, pp. 790-797, Mar./Apr. 2010

[17] Z. Q. Zhu, and J. T. Chen, "Advanced flux-switching permanent magnet brushless machines," IEEE Trans. Magn., vol. 46, no. 6, pp. 1447-1453, Jun. 2010.

[18] T. Raminosoa, C. Gerada, and M. Galea, "Design considerations for a fault-tolerant flux-switching permanent-magnet machine," IEEE Trans. Ind. Electron., vol. 58, no. 7, pp. 2818-2825, July 2011.

[19] J. T. Chen, Z. Q. Zhu, S. Iwasaki, and R. P. Deodhar, "A novel hybridexcited switched-flux brushless AC machine for EV/HEV applications," IEEE Trans. Veh. Technol., vol. 60, no. 4, pp.1365-1373, May 2011

[20] W. Hua, M. Cheng, Z. Q. Zhu, and D. Howe, "Analysis and optimization of back-emf waveform of a flux-switching PM motor," IEEE Trans. Energy Conversion, vol. 23, no. 3, pp. 727-733, Sep. 2008.

[21] J. T. Chen, Z. Q. Zhu, and D. Howe, "Stator and rotor pole combinations for multi-tooth flux-switching permanent-magnet brushless AC machines," IEEE Trans. Magn., vol. 44, no. 12, pp. 4659-4667, Dec. 2008.

[22] J. T. Chen, and Z. Q. Zhu, "Winding configuration and optimal stator and rotor pole combination of flux-switching PM brushless AC machines," IEEE Trans. Energy Conversion, vol. 25, no. 2, pp. 293-302, Jun. 2010.

[23] J. T. Chen, and Z. Q. Zhu, "Comparison of all- and alternate-poleswound flux-switching PM machines having different stator and rotor pole numbers," IEEE Trans. Ind. Appl.., vol. 46, no. 4, pp. 1406-1415, Jul./Aug. 2010.

[24] J. T. Chen, Z. Q. Zhu, S. Iwasaki, and R. P. Deodhar, "A novel E-core switched flux PM brushless AC machine," IEEE Trans. Ind. Appl.., vol 47, no. 3, pp. 1273-1282, May/Jun. 2011.

[25] J. T. Chen, Z. Q. Zhu, S. Iwasaki, and R. P. Deodhar, "Influence of slot opening on optimal stator and rotor pole combination and electromagnetic performance of switched-flux PM brushless AC machines," IEEE Trans. Ind. Appl.., vol. 47, no. 4, pp. 1681-1691, Jul./Aug. 2011

[26] T. M. Jahns, and W. L. Soong, "Pulsating torque minimization techniques for permanent magnet AC motor drives - A review," IEEE Trans. Ind. Electron., vol. 43, no. 2, pp. 321-330, Apr. 1996.

[27] H. Jia, M. Cheng, W. Hua, W. Zhao, and W. Li, "Torque ripple suppression in flux-switching PM motor by harmonic current injection based on voltage space-vector modulation," IEEE Trans. Magn., vol. 46, no. 6, pp. 1527-1530, Jun. 2010.

[28] W. Hua, and M. Cheng, "Cogging torque reduction of flux-switching permanent magnet machines without skewing," in Proc. $11^{\text {th }}$ Int. Electrical Machines and Systems Conf., Oct. 2008, pp. 3020-3025.

[29] M. J. Jin, Y. Wang, J. X. Shen, P. C. K. Luk, W. Fei, and C. F. Wang, "Cogging torque suppression in a permanent-magnet flux-switching integrated-starter-generator," IET Electr. Power Appl., vol. 4, no. 8, pp. 647-656, Sep. 2010.

[30] Y. Wang, M. J. Jin, W. Fei, and J. X. Shen, "Cogging torque reduction in PM flux-switching machines by rotor teeth axial pairing," IET Electr. Power Appl., vol. 4, no. 7, pp. 500-506, Aug. 2010.

[31] W. Fei, P. C. K. Luk, J. X. Shen, B. Xia, and Y. Wang, "Permanentmagnet flux-switching integrated starter generator with different rotor configurations for cogging torque and torque ripple mitigations," IEEE Trans. Ind. Appl.., vol. 47, no. 3, pp. 1247-1256, May/Jun. 2011.

[32] Z. X. Fang, Y. Wang, J. X. Shen, and Z. W. Huang, "Design and analysis of a novel flux-switching permanent magnet integrated-startergenerator," in Proc. $6^{\text {th }}$ IEE Power Electron, Machines and Drives Conf., Apr. 2008, pp. 106-110

[33] D. M. Ionel, and M. Popescu, "Ultrafast finite-element analysis of brushless PM machines based on space-time transformations," IEEE Trans. Ind. Appl.., vol. 47, no. 2, pp. 744-753, Mar./Apr. 2011.

[34] R. Islam, I. Husain, A. Fardoun, and K. Mclaughlin, "Permanent-magnet synchronous motor magnet designs with skewing for torque ripple and cogging torque reduction," IEEE Trans. Ind. Appl.., vol. 45, no. 1, pp. 152-160, Jan./Feb. 2009.

Weizhong Fei was born in Zhejiang, China, 1981. He received the B.Eng. and M.Sc. degrees in electrical engineering from Zhejiang University, Hangzhou, China, in 2004 and 2006, respectively, and the Ph.D degree in electrical engineering from Cranfield University, Shrivenham, U.K., in 2010.

He was a Research Associate with the University of Sheffield, U.K., from 2011 to 2012. He is currently a Research Fellow/Lecturer with Power Electronics and Machines Group in the School of Engineering, Cranfield University, Cranfield, U.K. His main research interests include design and applications of permanent magnet machines and drives.

Patrick Chi Kwong Luk (M'92-SM'08) was born in Hong Kong in 1960. He received the high diploma with merit (BSc) from Hong Kong Polytechnic University (PolyU), Kowloon, Hong Kong, in 1983, the Mphil from the University of Sheffield, Sheffield, U.K. in 1989, and the Ph.D from the University of Glamorgan, Wales, U.K. in 1992, all in electrical engineering.

He Started his career as assistant engineer at GEC (HK), then as application engineer at Polytek Engineering Co (HK), and as Researcher at the Industrial Centre, PolyU. Since 1988, he had held academic positions at the University of Glamorgan, Robert Gordon University, Aberdeen, U.K., and University of Hertfordshire, Hatfield, U.K. He joined Cranfield University as senior lecturer in 2002. He is the founder and head of the Power Electronics and Machines Group in the School of Engineering, Cranfield University, U.K. He has published over 100 papers on electric drives and energy conversion. His main research interests are in electrical drives for electric vehicles and renewable energy applications, and power electronics applications in future smart grids.

Jianxin Shen (M'98-SM'03) was born in Zhejiang, China, in 1969. He received the B.Eng. and M.Sc. degrees from Xi'an Jiaotong University, Xi'an, China, in 1991 and 1994, respectively, and the Ph.D degree from Zhejiang University, Hangzhou, China, in 1997, all in electrical engineering.

He was with Nanyang Technological University, Singapore (1997-1999), the University of Sheffield, Sheffield, U.K. (1999-2002), and IMRA Europe SAS, U.K. Research Centre, Brighton, U.K. (2002-2004). Since 2004, he has been a full Professor of electrical engineering at Zhejiang University. His current major research interests include design, control, and applications of permanent magnet machines and drives. 